Agnieszka Kruszwicka

Uniwersytet im. Adama Mickiewicza w Poznaniu

Wydziat Studiów Edukacyjnych

ORCID: 0000-0001-7834-2316

Michał Klichowski

Uniwersytet im. Adama Mickiewicza w Poznaniu

Wydziat Studiów Edukacyjnych

ORCID: 0000-0002-1614-926X

\title{
Cyberparki jako hybrydowe przestrzenie uczenia się: rozważania na marginesie projektu $\operatorname{COST}^{1}$
}

\begin{abstract}
Summary
CYBERPARKS AS HYBRID LEARNING SPACES: REFLECTIONS ON THE COST PROJECT

CyberParks will be hybrid spaces of future cities. Learning in CyberParks will take the form of technology-enhanced outdoor learning and will become an important concept that can be used in practice in order to provide an answer to numerous problems of educational institutions, related to students' lack of contact with nature and consolidation of their sedentary lifestyle. In this paper we discuss evidences from the CyberParks COST project and we present recommendations regarding the constructions of CyberParks. We point out, for example, that when designing CyberParks one has to think not only about the technological infrastructure, but also about making sitting spots for using learning technology. We also present the original project of such an object.
\end{abstract}

Keywords: public green spaces, outdoor learning, technology-enhanced learning, dual-task costs, smartphone

red. Paulina Marchlik

\footnotetext{
${ }^{1}$ Praca bazuje na analizach realizowanych przez drugiego autora w ramach grantu European Cooperation in Science and Technology: TUD COST Action TU1306. Wizualizacje rekomendacji zostały przygotowane przez pierwszego autora. Oboje autorzy uczestniczyli w procesie pisania tekstu.
} 


\section{Wprowadzenie}

We współczesnej urbanistyce jedno z centralnych miejsc zajmuje pytanie o to, co zrobić, by w miastach były wysokiej jakości tereny zielone (Lindholst i in. 2016), a także o to, jak to zrobić, by mieszkańcy miast realnie wykorzystywali potencjał tego typu miejsc (Thomas 2014), przezwyciężając tym samym obecną kulturową tendencję do przebywania w miejskich przestrzeniach zamkniętych (Duarte i in. 2015). Jednym z najnowszych pomysłów na takie ulepszenie i uatrakcyjnienie miejskich przestrzeni zielonych jest dodanie do nich dodatkowego, cyfrowego wymiaru, a zatem przekonwertowanie tych przestrzeni do postaci hybrydowej - łączącej naturę i technikę (Menezes i Smaniotto Costa 2017; Klichowski 2019). Taki digitalny kontekst ma stymulować obywateli miast do odsunięcia się choć na chwilę od siedzącego, wirtualnego życia i zachęcać do zintensyfikowania własnej aktywnej partycypacji w „życiu na zewnątrz” (Raiyn 2015).

Hybrydowe przestrzenie powinny być postrzegane jako bardzo innowacyjne, tradycyjnie bowiem zielone (naturalne) zakątki miast i wszelkie cyfrowe domeny, rozpatrywane były jako skrajnie od siebie odseparowane (Thomas 2014). W ostatnich latach używanie mobilnych technologii w publicznych przestrzeniach zielonych stało się jednak zupełnie powszechne. Każdego dnia można spotkać osoby spacerujące w parku ze smartfonem w ręce, czy siedzące na parkowych ławkach jednostki, przeszukujące zasoby Internetu na tabletach (Duarte i in. 2015). Korzyści z połączenia natury i techniki, uzmysławiają także wyniki najnowszych badań. Sugerują one na przykład, że mobilne narzędzia mogą stymulować aktywność fizyczną na świeżym powietrzu (Barnett i in. 2014; Hurvitz i in. 2014) i zachęcać do spędzania czasu w kontakcie z przyrodą (Lubans $i$ in. 2014; Suchocka i in. 2017). Hybrydowa przestrzeń to jednak coś więcej niż park, w którym ludzie korzystają ze smartfonów. Musi być to inteligentne środowisko, w którym różnego typu czujniki i komputery monitorują aktywność użytkowników i reagują adekwatnie do niej, niejako dostosowując funkcjonowanie parku do aktualnego zachowania ludzi, którzy się tam znajdują, czy zachęcając ich do podjęcia określonego typu aktywności (Thomas 2014). Cyfrowy wymiar miejskiego parku, to więc zaawansowana technologiczna infrastruktura zaimplementowana w jego najpierwotniejszą tkankę (Menezes i Smaniotto Costa 2017).

Idea przestrzeni hybrydowych pojawiła się najpierw w sztuce, w artystycznych działaniach, w których różnego typu obiekty technologiczne, wykorzystywano do pobudzenia uwagi użytkowników parków (Thomas 2014). Później ideę tę przejęli miejscy innowatorzy, którzy postanowili zachęcić mieszkańców 
miast do pracy na własnych laptopach, tabletach czy smartfonach w parkach, wyposażając je na przykład w bezpłatne Wi-Fi czy źródła zasilania (Smaniotto Costa $\mathrm{i}$ in. 2015). Finalnie, naukowcy zwrócili uwagę na społeczny i poznawczy potencjał takiego cybernetyczno-przestrzennego doświadczenia, torując tym samym drogę dla powstania idei cyberparków (Ioannidis i in. 2015; Smaniotto Costa i Suklje-Erjavec 2015), czyli publicznych terenów zielonych w mieście, w których można korzystać z mobilnych narzędzi technologicznych, i których technologiczna infrastruktura zachęca do podejmowania różnorakich aktywności poznawczych i fizycznych (Klichowski i Smaniotto Costa 2015; Klichowski i in. 2015; Klichowski 2017).

Koncepcja cyberparków została naukowo rozwinięta przez europejskich badaczy zrzeszonych w międzynarodowym projekcie realizowanym w latach 20142018 i finansowanym przez European Cooperation in Science and Technology (TUD COST Action TU1306), w ramach którego Michał Klichowski opracował i eksperymentalnie zweryfikował koncepcję uczenia się w cyberparkach. W artykule tym, bazując na raporcie z tego projektu (Klichowski 2017), przedstawimy (w niemal telegraficznym skrócie, a tym samym i w pewny uproszczeniu) założenia i technologiczne uwarunkowania tego konceptu. Omówimy także wyniki badań nad efektywnością uczenia się w przestrzeniach bliskich definicji cyberparku, zarówno te rekonstruowane w wymienionym opracowaniu, jak i w nim raportowane. Naszą narrację uzasadniamy tym, że dotychczas dane te nie zostały opublikowane w języku polskim. Nawet więc takie skrótowe omówienia edukacyjnych kontekstów cyberparków uznajemy za istotne dla polskiego czytelnika (czytelników pragnących zagłębić się w teoretyczno-empiryczne rozważania dotyczące uczenia się w cyberparkach odsyłamy do wskazanego raportu - Klichowski 2017 oraz do pozostałych anglojęzycznych publikacji na ten temat: Klichowski i Smaniotto Costa 2015; Klichowski i in. 2015; Klichowski i Patricio 2017; Bonanno i in. 2019; Klichowski 2019). Artykuł zakończymy rekomendacjami praktycznymi, sporządzonymi na marginesie omawianego projektu oraz prezentacją autorskiej propozycji układu cyberparku i wizualizacji jednego z kluczowych jego obiektów. I właśnie przedstawienie tych pedagogicznych wskazówek uznajemy za najważniejszy cel niniejszej pracy. 


\section{Założenia i technologiczne uwarunkowania uczenia się w cyberparkach}

Badacze są zgodni co do tego, że naturalne otoczenie, wzbogacone o technologiczny wymiar, stanowi bardzo atrakcyjną przestrzeń uczenia się (Land i Zimmerman 2015). Co więcej, zauważają oni, że publiczne przestrzenie zielone wyposażone w rozwiązania technologiczne, mogą efektywnie stymulować poznawczy rozwój mieszkańców miast (Kukulska-Hulme i Jones 2012), a także mogą stanowić „zdrową” i intrygującą przestrzeń uczenia się dzieci i młodzieży uczęszczających do miejskich szkół (Smith i in. 2012). Koncepcja cyberparków wydaje się więc fascynująca z perspektywy pedagogicznej. Oto bowiem miejskie parki mogą stać się przestrzeniami uczenia się, zapewniającego uczniom bliskość natury, stymulującego ich do aktywności fizycznej i umożliwiającego poznawanie własnego otoczenia, poprzez wspieraną technologicznie jego eksplorację (Klichowski 2017; Klichowski i Patricio 2017).

Technologicznym rozwiązaniem możliwym do wykorzystania podczas uczenia się w cyberparkach może być na przykład połączenie smartfona z e-biblioteką. W takich warunkach uczniowie mogą dokonywać obserwacji wybranych obiektów przyrodniczych wraz z tworzeniem notatek (w formie tekstu, filmu, zdjęcia, dźwięku itp.) na ich temat poprzez smartfona, a następnie skonfrontować własne spostrzeżenia z informacjami znajdującymi się w e-bibliotece (Hung i in. 2010).

Inną ciekawą technologią uczenia się, którą można by zaimplementować w tkankę cyberparków są QR (ang. Quick Response) kody. W tym przypadku uczniowie wyposażeni w smartfony lub tablety, spacerując po parku, mogliby skanować znajdujące się przy różnych jego obiektach (na przykład przy drzewach, krzewach czy pomnikach) kody QR i otrzymywać na swoje mobilne urządzenia ciekawe informacje na ich temat, które mogą następnie jakoś przekształcić i uzupełnić, dodając na przykład nowe zdjęcie czy opis (Perez-Sanagustin i in. 2016; Lai i in. 2013). W cyberparkach mogą także znajdować się komputery połączone z Kinectami. Taki system mógłby rozpoznawać różnorakie ruchy uczniów i na ich podstawie uruchamiać na wyświetlaczach krótkie filmy edukacyjne dotyczące danego ciekawego miejsca w parku (Pan i in. 2014).

Najefektywniejszą technologią uczenia się w cyberparkach wydaje się jednak GPS (Perez-Sanagustin i in. 2015; 2016). Pozwala on bowiem na to, by uruchamiana na smartfonie lub tablecie aplikacja dostarczała uczniowi materiały edukacyjne dobrane do miejsca, w którym się właśnie znajduje. I tak na przykład, gdy uczeń zatrzyma się w pobliżu ciekawego gatunku drzewa, na jego smartfonie 
mogłaby uruchomić się animacja ujawniająca jego budowę (Mannheimer Zydney i Warner 2016) lub obraz rozszerzający (wykorzystując technologię $A R+$ ), ukazujący na przykład, jak wygląda to drzewo w innych porach roku (Bonanno i in. 2017). Ponadto aplikacja ta może prowadzić uczniów do interesujących miejsc w parku, tak by poznawali lokalną historię lub geografię terenu (Schwartz 2016), albo wskazywać im zadania do wykonania w danym punkcie, na przykład obliczenie objętości zbiornika wodnego znajdującego się przy parkowej fontannie (Ludwig i Jesberg 2015). GPS pozwala także „tagować” wybrane miejsca, tak więc uczniowie mogliby oznaczać intrygujące skwery i upowszechniać multimedialne notatki na ich temat, a nauczyciele byliby zdolni zdalnie monitorować ich postępy (Pierdicca i in. 2017; Lister 2017).

\section{Badania nad uczeniem się w cyberparkach}

Istnieje wyraźny deficyt badań dotyczących wspomaganego technologicznie uczenia się na zewnątrz (Hung i in. 2012). Metaanalizy pokazują na przykład, że tylko nieco powyżej piętnaście procent badań edukacyjnych dotyczy uczenia się na zewnątrz, z czego bardzo niewiele z nich analizuje jakiegokolwiek typu technologiczne jego wspomaganie (Sung $i$ in. 2016). Ponadto $w$ tych nielicznych badaniach najczęściej studiowano efektywność uczenia się poprzez zbieranie opinii uczniów na jego temat, a nie badano realnych jego efektów (Huang i Chiu 2015). Dotychczas tylko trzy zespoły naukowców podjęły się rzetelnego, eksperymentalnego zweryfikowania efektywności technologicznie wspomaganego uczenia się na terenach zielonych. Badania te pokazują jednoznacznie, że tego typu strategia uczenia się jest znacznie efektywniejsza od tradycyjnych (nie opartych na nowych technologiach) form uczenia się na zewnątrz (Hsiao i in. 2010; Huang i in. 2016), ale także, że jest ona efektywniejsza od technologiczne wspomaganego uczenia się w klasie (Su i Cheng 2015).

Jednak w żadnym z tych badań nie uwzględniono fundamentalnej dla technologicznie wspomaganego uczenia się na zewnątrz kwestii, a mianowicie interferencji aktywności poznawczej z aktywnością fizyczną. A takie połączenie, jak sugerują najnowsze badania z zakresu neuronauki, może przynosić bardzo negatywne skutki. W ostatnich latach zauważono, że obszary mózgu powiązane $\mathrm{z}$ wyższymi procesami poznawczymi są silnie zaangażowane $\mathrm{w}$ wykonywanie także prostych i dotychczas uznawanych za zautomatyzowane rodzajów aktywności fizycznej, takich jak na przykład chód, co sugeruje, że choć sobie tego nie 
uświadamiamy, nawet najprostsze czynności motoryczne podlegają poznawczej kontroli (Harada i in. 2009). Dlatego też, jeśli idąca osoba zacznie wykonywać jakieś zadanie poznawcze, natychmiast tempo jej chodu spada i zaczyna być narażona na upadek (Al-Yahya i in. 2011). Mózg, nie mogąc bowiem w pełni kontrolować przemieszczania się, musi je po prostu w jakimś stopniu wyhamować, choć takie wyhamowanie i tak nie zapewnia pełnego bezpieczeństwa (Bonato i in. 2012; Pothier i in. 2014). Co ciekawe, działa to także w drugą stronę: Gdy podczas zadania poznawczego jednostka zacznie wykonywać jakąś czynność motoryczną, efektywność realizacji tego zadania natychmiast spada (Takeuchi $\mathrm{i}$ in. 2016). Taki efekt nazywany jest kosztem podwójnego zadania i jest on tym większy, im większa jest trudność zadania poznawczego lub intensywność ruchu (Yuan i in. 2016).

Jedną z najpowszechniejszych współcześnie sytuacji, w których doświadczyć można kosztów podwójnego zadania, jest używanie smartfona podczas chodu (Takeuchi i in. 2016). Zarówno opracowania naukowe, jak i statystyki medyczne, potwierdzają, iż tego typu zachowanie niesie ze sobą poważne ryzyko o charakterze motorycznym (Nagamatsu i in. 2011; Yamada i in. 2011). Do roku 2017 nie dysponowaliśmy jednak wynikami badań, w których analizowano, w jak dużym stopniu spacerowanie ze smartfonem osłabia procesy poznawcze (Bonanno i in. 2019). A jest to kwestia kluczowa, bowiem gdyby osłabienie to było istotne, wyartykułowana tu idea uczenia się w cyberparkach, jako pewnego typu połączenia aktywności poznawczej - realizowanej właśnie poprzez smartfony (albo tablety czy inne tego rodzaju narzędzia) - z aktywnością fizyczną (na przykład spacerowaniem w parku), nie tylko odnosiłaby się do czynności motorycznie niebezpiecznej, ale też poznawczo nieefektywnej.

By rzucić nieco światła na ten problem, w ramach omawianego tu projektu przeprowadzono dwa eksperymenty, podczas których uczestnicy uczyli się w parku z wykorzystaniem smartfonów, czasem łącząc te działanie z aktywnością fizyczną, a czasem nie. Grupa kontrolna wykonywała te same zadania w klasie. Podczas eksperymentu uczniowie mieli na głowach mobilny encefalograf, pozwalający na monitorowanie aktywności ich mózgu. Okazało się, że uczenie się w parku było dużo efektywniejsze od tego realizowanego w klasie. Jednak efekty zadań wykonywanych w połączeniu z aktywnością fizyczną były istotnie niższe od tych, z nią niepołączonych, a zapisy fal mózgowych wskazywały, iż łącząc działania intelektualne i motoryczne, uczniowie mieli problemy z koncentracją na zadaniu poznawczym i przejawiali podwyższony poziom stresu (Klichowski 2017). Wyniki te sugerują, iż cyberparki, jeśli mają stać się hybrydo- 
wymi przestrzeniami uczenia się, powinny być projektowane w nieco inny, niż pierwotnie założono, sposób.

\section{Podsumowanie i rekomendacje}

Uczenie się w cyberparkach to bardzo ciekawa propozycja kierowana do mieszkańców współczesnych (i przyszłych) miast. Jednak nim cyberparki staną się przestrzeniami efektywnego uczenia się, ich idea musi zostać w pewnym sensie przedefiniowana: W cyberparku ludzie powinni być aktywni fizycznie, jednak aktywność ta powinna być odseparowana od celowej aktywności poznawczej.

Cyberparki powinny być więc tak zaprojektowane, by osoby uczące się w nich mogły usiąść na ławce, trawie czy w innym miejscu, i uczyć się z wykorzystaniem technologii niewymagających od niego ruchu. Ponadto usytuowanie miejsc do siedzenia powinno być tak pomyślane, by uczący się, podczas przerw, mogli być aktywni fizycznie. Projektując cyberparki należy więc nie tylko myśleć o ich technologicznej infrastrukturze, ale także o tym, by były w nich miejsca, pozwalające na wygodne siedzenie i korzystanie z mobilnych technologii (Klichowski 2017). W cyberparkach powinny być więc na przykład stoły z bezprzewodowymi ładowarkami, ławki wyposażone w źródła zasilania, a może nawet coś na kształt zewnętrznych klas. Autorską propozycję układu technologiczno-przestrzennego cyberparku prezentujemy na rycinie 1 .

Kluczowe w cyberparkach wydają się być różnego typu altany, nie tylko posiadające dostęp do mediów elektronicznych, ale także dające cień lub chroniące przed deszczem. Autorski projekt takiego pawilonu przedstawiamy na rycinie 2 .

Po uwzględnieniu powyższych rekomendacji uczenie się w cyberparkach staje się bardzo ważną koncepcją, której implementacja do rzeczywistości edukacyjnej może być odpowiedzią na liczne problemy współczesnych instytucji oświatowych, związanych na przykład z brakiem częstego kontaktu uczniów z przyrodą i utrwalaniem ich siedzącego trybu życia. Koncepcja uczenia się w cyberparkach wydaje się ponadto reprezentować pewne zbalansowane (zdrowe) podejście do poziomu użycia technologii w edukacji (Thomas 2011). W cyberparku uczniowie mają się bowiem uczyć z wykorzystaniem technologii, ale mają też być blisko świata natury, a zatem rzeczywistości niestechnicyzowanej. 
Rycina 1. Propozycja układu przestrzenno-technologicznego cyberparku

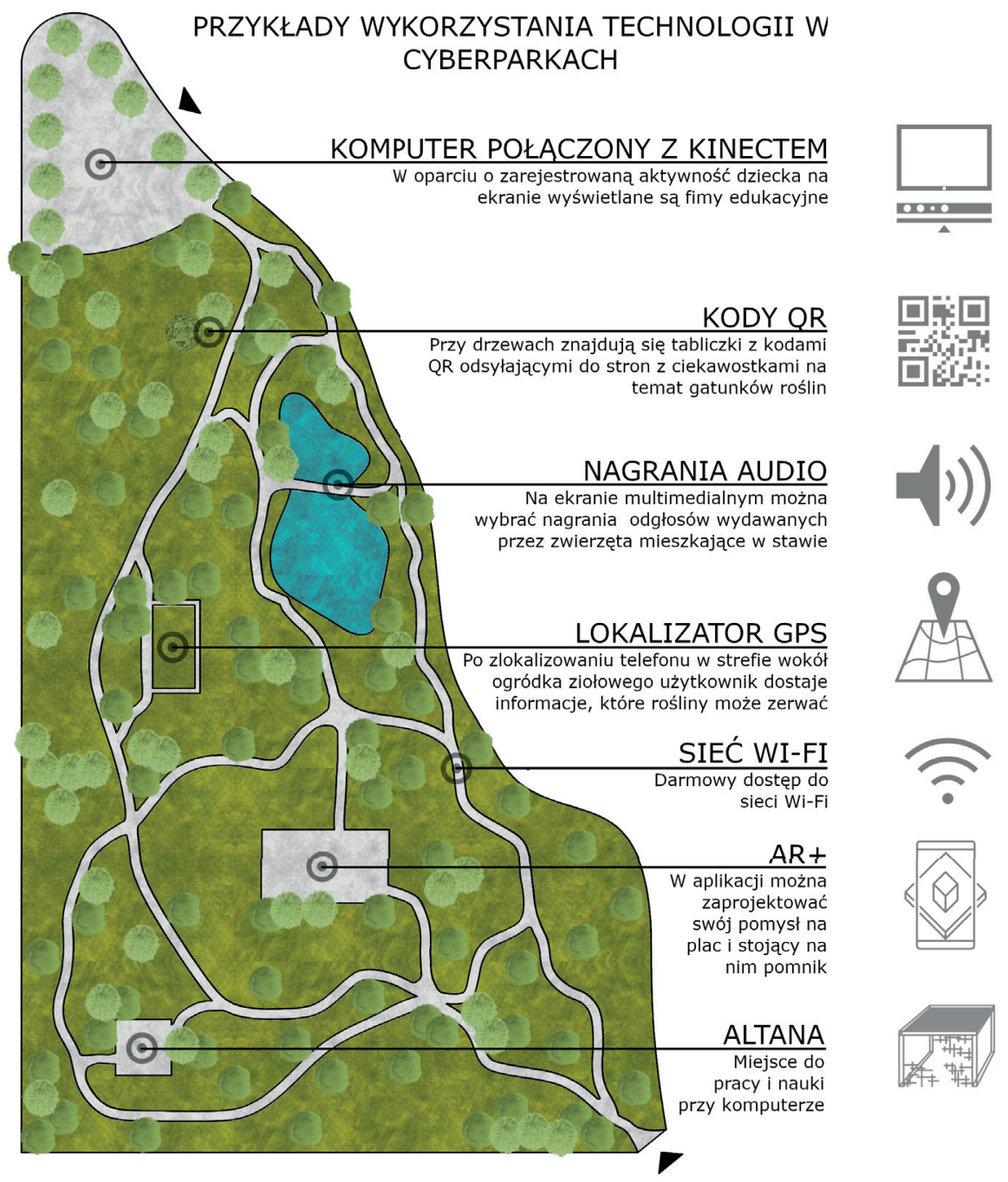

Opis: W całym cyberparku jest bezpłatne Wi-Fi. W miejscach do siedzenia (np. w altanach) jest dostęp do prądu. Altany są tak zlokalizowane, by uczący się, podczas przerw, mogli być aktywni fizycznie. Wszystkie rozwiązania technologiczne powiązane są z konkretnymi elementami przestrzeni parku. 
Rycina 2. Projekt altany dla cyberparków
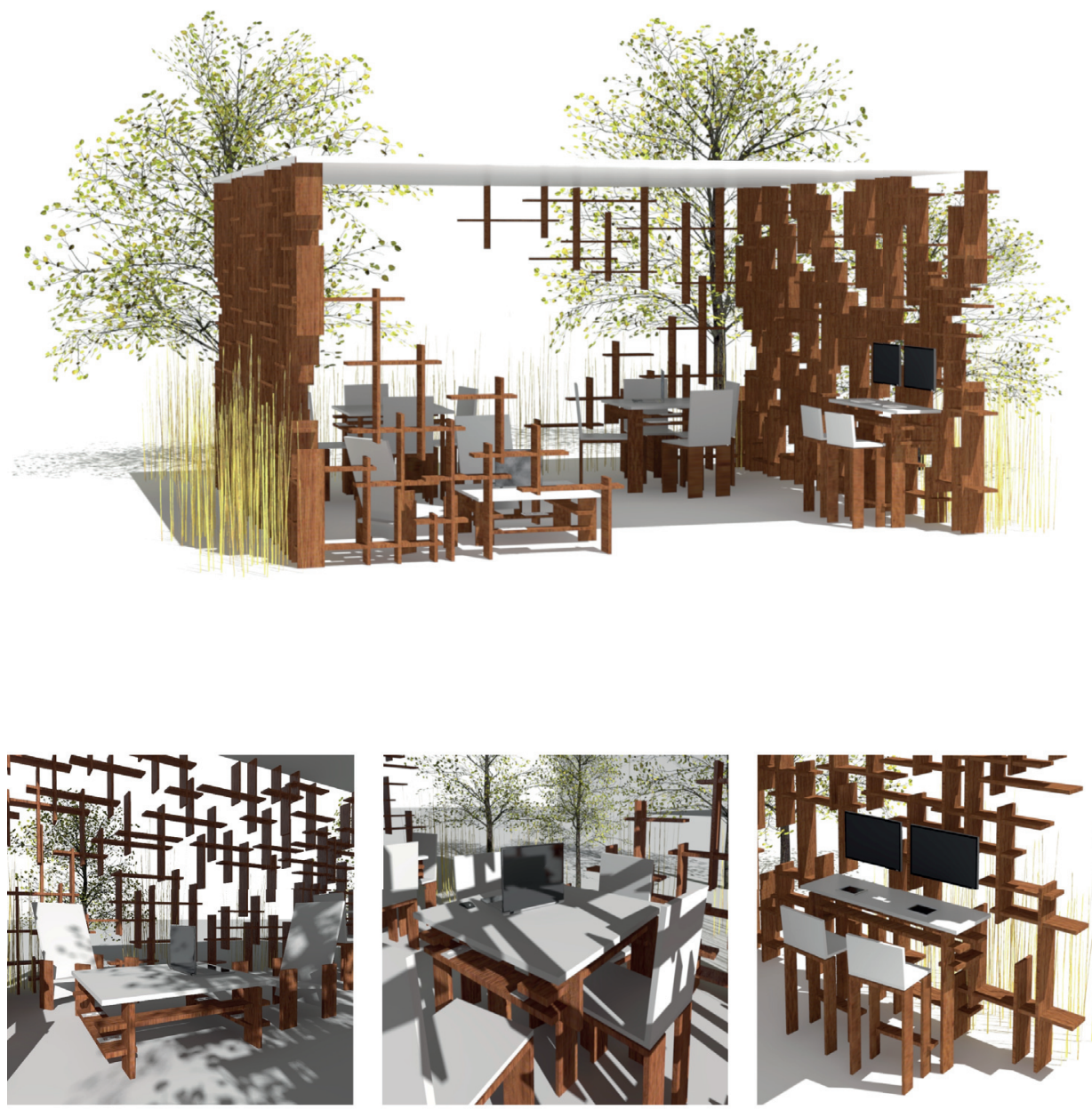

Opis: Pawilon ten jest tak pomyślany, by uczące się w parku osoby mogły wygodnie usiąść, podłączyć własne urządzenia do zasilania lub skorzystać z komputerów w nim się znajdujących, ale także schronić się przed deszczem czy zbyt intensywnym nasłonecznieniem. Siedziska umożliwiają pracę indywidualną lub grupową. Materiały, z których altana jest wykonana nawiązują do idei hybrydy natury i techniki. 


\section{Bibliografia}

Al-Yahya E., Dawes H., Smith L., Dennis A., Howells K. i Cockburn J. 2011. Cognitive motor interference while walking: a systematic review and meta-analysis, „Neuroscience \& Biobehavioral Reviews", nr 35, s. 715-728.

Barnett L.M., Bangay S., McKenzie S. i Ridgers N.D. 2013. Active gaming as a mechanism to promote physical activity and fundamental movement skill in children, „Frontiers in Public Health”, nr 1, s. $1-3$.

Bonanno P., Klichowski M. i Lister P. 2019. A pedagogical model for CyberParks, [w:] CyberParks the interface between people, places and technology, red. C. Smaniotto Costa i I. Suklje-Erjavec, T. Kenna, M. de Lange, K. Ioannidis, G. Maksymiuk i M. de Waal Springer, Cham, s. 294-307.

Bonanno P., Martinez A.B., Pierdicca R., Marcheggiani E., Franco F.J.A. i Malinverni E.S. 2017. A connectivist approach to smart city learning: Valletta city case-study, [w:] Enhancing Places through Technology. Proceedings from the ICiTy conference, red. A. Zammit i T. Kenna, Edicoes Universitarias Lusofonas, Lisbon, s. 69-81.

Bonato M., Priftis K., Spironelli C., Lisi M., Umilta C. i Zorzi M. 2012. Dual-tasks induce awareness deficits for the contralesional hemispace, „Frontiers in Human Neuroscience”, nr 129, s. 1-1.

Duarte T., Smaniotto Costa C., Mateus D., Menezes M. i Bahillo A. 2015. Pervasive open public spaces - the amalgamation of information and communication technologies into open public spaces. Reflections of the COST Action - TU 1306 CyberParks, [w:] Projects for an inclusive city. Social integration through urban growth strategies, red. O. Marina i A. Armando, City of Skopje, Skopje, s. 212-225.

Harada T., Miyai I., Suzuki M. i Kubota K. 2009. Gait capacity affects cortical activation patterns related to speed control in the elderly, „Experimental Brain Research”, nr 193, s. 445-454.

Hsiao H.-S., Lin C.-C., Feng R.-T. i Li K.J. 2010. Location based services for outdoor ecological learning system: design and implementation, ,Journal of Educational Technology \& Society”, nr 13, s. $98-111$.

Huang T.C., Chen C.-C. i Chou Y.-W. 2016. Animating eco-education: to see, feel, and discover in an augmented reality-based experiential learning environment, „Computers \& Education”, nr 96, s. 72-82.

Huang Y.-M. i Chiu P.-S. 2015. The effectiveness of the meaningful learning-based evaluation for different achieving students in a ubiquitous learning context, „Computers \& Education”, nr 87, s. 243-253.

Hung P.-H., Hwang G.-J., Su, I-H. i Lin I-H. 2012. A concept-map integrated dynamic assessment system for improving ecology observation competences in mobile learning activities, „Turkish Online Journal of Educational Technology - TOJET", nr 11, s. 10-19.

Hung P.-H., Lin, Y.-F. i Hwang G.-J. 2010. Formative assessment design for PDA integrated ecology observation, „Educational Technology \& Society”, nr 13, s. 33-42.

Hurvitz P.M., Moudon A.V., Kang B., Saelens B.E. i Duncan G.E. 2014. Emerging technologies for assessing physical activity behaviors in space and time, „Frontiers in Public Health”, nr 2, s. 1-15.

Ioannidis K., Smaniotto Costa, C., Suklje-Erjavec I., Menezes, M. i Martinez A.B. 2015. The lure of CyberPark - synergistic outdoor interactions between public spaces, users and locative technologies, [w:] Hybrid city 2015: data to the people, red. I. Theona i C. Dimitris, URIAC, Athens, s. 272-281.

Klichowski M. i Patricio C. 2017. Does the human brain really like ICT tools and being outdoors? A brief overview of the cognitive neuroscience perspective of the CyberParks concept, [w:] Enhancing Places 
through Technology. Proceedings from the ICiTy conference, red. A. Zammit i T. Kenna, Edicoes Universitarias Lusofonas, Lisbon, s. 223-239.

Klichowski M. i Smaniotto Costa C. 2015. How do pre-service teachers rate ICT opportunity for education? A study in perspective of the SCOT theory, „Culture and Education”, nr 4, s. 152-168.

Klichowski M., Bonanno P., Jaskulska S., Smaniotto Costa C., de Lange M. i Klauser F. 2015. CyberParks as a new context for smart education: theoretical background, assumptions, and pre-service teachers' rating, „American Journal of Educational Research”, nr 3, s. 1-10.

Klichowski M. 2017. Learning in CyberParks. A theoretical and empirical study, Adam Mickiewicz University Press, Poznan.

Klichowski M. 2019. Learning in hybrid spaces as a technology-enhanced outdoor learning: Key terms, [w:] Neighbourhood \& City - Between digital and analogue perspectives, red. M. Menezes i C. Smaniotto Costa, Edicoes Universitarias Lusofonas, Lisbon, s. 59-68.

Kukulska-Hulme A. i Jones C. 2012. The next generation: design and the infrastructure for learning in a mobile and networked world, [w:] Informed design of educational technologies in higher education: enhanced learning and teaching, red. A.D. Olofsson i J.O. Lindberg, Information Science Reference, Hershey, s. 57-78.

Lai H.-C., Chang C.-Y., Li W.-S., Fan Y.-L. i Wu Y.-T. 2013. The implementation of mobile learning in outdoor education: application of $Q R$ codes, „British Journal of Educational Technology”, $\mathrm{nr} 44$, s. E57-E62.

Land S.M. i Zimmerman H.T. 2015. Socio-technical dimensions of an outdoor mobile learning environment: a three-phase design-based research investigation, „Educational Technology Research and Development", nr 63, s. 229-255.

Lindholst A.C., Konijnendijk van den Bosch C.C., Kjoller C.P., Sullivan S., Kristoffersson A., Fors H. i Nilsson K. 2016. Urban green space qualities reframed toward a public value management paradigm: the case of the Nordic Green Space Award, „Urban Forestry \& Urban Greening”, nr 17, s. 166-176.

Lister P.J. 2017. Evaluating smart city learning, [w:] Enhancing Places through Technology. Proceedings from the ICiTy conference, red. A. Zammit i T. Kenna, Edicoes Universitarias Lusofonas, Lisbon, s. 241-255.

Lubans D.R., Smith J.J., Skinner G. i Morgan P.J. 2014. Development and implementation of a smartphone application to promote physical activity and reduce screen-time in adolescent boys, „Frontiers in Public Health", nr 2, s. 1-11.

Ludwig M. i Jesberg J. 2015. Using mobile technology to provide outdoor modelling tasks - the mathcitymap-project, „Procedia - Social and Behavioral Sciences”, nr 191, s. 2776-2781.

Mannheimer Zydney J. i Warner Z. 2016. Mobile apps for science learning: review of research, „Computers \& Education", nr 94, s. 1-17.

Menezes M. i Smaniotto Costa C. 2017. People, public space, digital technology and social practice: an ethnographic approach, [w:] Enhancing Places through Technology. Proceedings from the ICiTy conference, red. A. Zammit i T. Kenna, Edicoes Universitarias Lusofonas, Lisbon, s. 167-180.

Nagamatsu L.S., Voss M., Neider M.B., Gaspar J.G., Handy T.C., Kramer A.F. i Liu-Ambrose T.Y. 2011. Increased cognitive load leads to impaired mobility decisions in seniors at risk for falls, „Psychology and Aging”, nr 26, s. 253-259.

Pan W.F., Tu S.-C. i Chien M.-Y. 2014. Feasibility analysis of improving on-campus learning paths via a depth sensor, „Interactive Learning Environments”, nr 22, s. 514-528. 
Perez-Sanagustin M., Munoz-Merino, P.J., Alario-Hoyos C., Soldani X. i Delgado Kloos C. 2015. Lessons learned from the design of situated learning environments to support collaborative knowledge construction, „Computers \& Education”, nr 87, s. 70-82.

Perez-Sanagustin M., Parra D., Verdugo R., Garcia-Galleguillos G. i Nussbaum M. 2016. Using QR codes to increase user engagement in museum-like spaces, „Computers in Human Behavior”, nr 60, s. 73-85.

Pierdicca R., Malinverni E.S., Khromova A., Marcheggiani E., Bonanno P., Franco F.J.A. i Martinez A.B. 2017. The integration of an augmented reality module within the Way - Cyberparks Ass. The case study of Valletta city, [w:] Enhancing Places through Technology. Proceedings from the ICiTy conference, red. A. Zammit i T. Kenna, Edicoes Universitarias Lusofonas, Lisbon, s. 57-68.

Pothier K., Benguigui N., Kulpa R. i Chavoix C. 2014. Multiple object tracking while walking: similarities and differences between young, young-old, and old-old adults, ,Journals of Gerontology Series B: Psychological Sciences and Social Sciences", nr 70, s. 840-849.

Raiyn J. 2015. Modern information and communication technology and their application in CyberParks, ,Journal of Multidisciplinary Engineering Science and Technology”, nr 2, s. 2178-2183.

Schwartz J.E. 2016. Unlocking thinking through and about GPS, „Children's Technology \& Engineering", nr 20, s. 12-15.

Smaniotto Costa C. i Suklje-Erjavec I. 2015. Information and communication technologies and the public spaces: reflections on exploring a new relationship - first results from COST Action CyberParks TU 1306, „Proceedings of EURO ELECS”, s. 1797-1806.

Smaniotto Costa C., Menezes M. i Suklje-Erjavec I. 2015. How can information and communication technologies be used to better understand the way people use public spaces: first reflections of the COST Action CyberParks - TU 1306, [w:] Planeamento cultural urbano em areas metropolitanas, red. C.A. Marques, Editora Caleidoscopio, Casal de Cambra, s. 1-7.

Smith C., Bradley C., Cook J. i Pratt-Adams S. 2013. Designing for active learning: putting learning into context with mobile devices, [w:] Informed design of educational technologies in higher education: enhanced learning and teaching, red. A.D. Olofsson i J.O. Lindberg, Information Science Reference, Hershey, s. 307-329.

Su C.-H. i Cheng C-H. 2015. A mobile gamification learning system for improving the learning motivation and achievements, ,Journal of Computer Assisted Learning”, nr 31, s. 268-286.

Suchocka M., Kimic K., Maksymiuk G. i Kolodynska N. 2017. Outdoor hotspots as a tool for enhancing healthy lifestyles of ICT users, [w:] Enhancing Places through Technology. Proceedings from the ICiTy conference, red. A. Zammit i T. Kenna, Edicoes Universitarias Lusofonas, Lisbon, s. 153-165.

Sung Y.-T., Chang K.-E. i Liu T.-C. 2016. The effects of integrating mobile devices with teaching and learning on students' learning performance: a meta-analysis and research synthesis, „Computers \& Education", nr 94, s. 252-275.

Takeuchi N., Mori T., Suzukamo Y., Tanaka, N. i Izumi S.-I. 2016. Parallel processing of cognitive and physical demands in left and right prefrontal cortices during smartphone use while walking, „BMC Neuroscience", nr 17, s. 1-11.

Thomas M. 2011. Digital education: opportunities, challenges, and responsibilities, [w:] Digital education. Opportunities for social collaboration, red. M. Thomas, Palgrave Macmillan, New York, s. $1-5$.

Thomas S. 2014. CyberParks will be intelligent spaces embedded with sensors and computers, „The Conversation". 
Yamada M., Aoyama T., Okamoto K., Nagai K., Tanaka B. i Takemura T. 2011. Using a smartphone while walking: a measure of dual-tasking ability as a falls risk assessment tool, „Age and Ageing”, nr 40, s. 516-519.

Yuan P., Koppelmans V., Reuter-Lorenz P.A., De Dios Y.E., Gadd NE., Wood S.J., Riascos R., Kofman I.S., Bloomberg J.J., Mulavara A.P. i Seidler R.D. 2016. Increased brain activation for dual tasking with 70-days head-down bed rest, „Frontiers in Systems Neuroscience”, nr 10, s. $1-14$. 
